\title{
Macroscopic Findings Directionality
}

National Cancer Institute

\section{Source}

National Cancer Institute. Macroscopic Findings Directionality. NCI Thesaurus. Code C119855.

A qualifier for the direction on the body the macroscopic findings test is performed. 